\title{
Novel ripple reduction method using three-level inverters with unipolar PWM
}

\author{
Paiboon Kiatsookkanatorn ${ }^{1}$, Napat Watjanatepin ${ }^{2}$ \\ ${ }^{1}$ Department of Electrical Engineering, Rajamangala University of Technology Suvarnabhumi, Thailand \\ ${ }^{2}$ Solar Energy Research and Technology Transfer Center (SERTTC), \\ Rajamangala University of Technology Suvarnabhumi, Thailand
}

\begin{tabular}{l} 
Article Info \\
\hline Article history: \\
Received Mar 7, 2021 \\
Revised Mar 26, 2021 \\
Accepted Apr 2, 2021 \\
\hline
\end{tabular}

\section{Keywords:}

Carrier-based modulation

Three-level inverters

Two-level inverters

Voltage and current ripple

\begin{abstract}
This paper proposes a novel method to reduce voltage and current ripple for the inverters by using three-level inverters with unipolar pulse width modulation (PWM) (3LFB-2U). A simple technique of switching signal generation by using carrier-based dipolar modulation of three-phase threelevel inverters is extended to single-phase inverters that can be done by generating all possible switching patterns of the single-phase three-level inverters. Moreover, the concept of carrier-based dipolar modulation and the construction of reference voltages from desired output voltage and added zero voltage to control unipolar switching is also shown. The research results reveal that the proposed method can reduce the voltage and current ripple. Furthermore, the voltage and current harmonics can reduce by $27.77 \%$ and $1.79 \%$, respectively less than two-level inverters without a loss of a simple modulation to generate the switching signals.
\end{abstract}

This is an open access article under the CC BY-SA license.

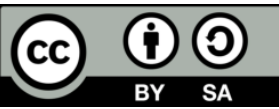

\author{
Corresponding Author: \\ Napat Watjanatepin \\ Solar Energy Research and Technology Transfer Center (SERTTC) \\ Rajamangala University of Technology Suvarnabhumi \\ 7/1 Nonthaburi-1, Nonthaburi, 11000, Thailand \\ Email: napat.w@rmutsb.ac.th
}

\section{INTRODUCTION}

Single-phase inverters have been widely applied to grid -connected inverters for low voltage and low power [1], [2]. These inverters have many requirements for grid codes [3]. The current harmonic is one of the important and interesting grid requirements. This harmonic is related directly to pulse width modulation (PWM) strategies [4]. For two-level full-bridge inverters [5], bipolar modulation is one of the modulation methods that produce the signal to drive the switch easily. However, the ripple of the voltage and current are normaly high, which causes a high harmonic voltage and a harmonic current as shown relationship in [6]. To reduce the ripple, unipolar modulation needs to be used instead. The unipolar modulation also makes the switch a unipolar switching, which reduces the ripple voltage, current, and the harmonic. However, the switching losses are high. R. Lai and K. D. T. Ngo [7], hybrid modulation is proposed to reduce switching losses but the ripple and the harmonic values remain high. Therefore, if the ripple and harmonic values are to be lowered, a large filter circuit will be required [8], [9]. This type of circuit suffers a high loss [10], [11] and the effect of inductance saturation [12].

Regarding three-level inverters, they are utilized to solve problems of two-level inverters, such as the switch voltage stress, the harmonic value, and the switching losses. The input voltage of three-level inverters stems from the capacitors connected in a series to divide the direct current (DC) bus voltage [13]-[16]. Then, the voltage drop of capacitors is only about half of the DC bus voltage. Therefore, if the switching patterns of 
three-level full-bridge inverters are controlled by using unipolar switching that is no direct voltage transition from positive bus voltage to negative bus voltage, the voltage level transition of output is only half of the DC bus voltage. As a result of the decrease in the ripple output, the harmonic components will be reduced as well.

However, the modulation of three-level inverters cannot be done by directly using the modulation of two-level inverters. For this reason, recent research by [17]-[24] has developed modulation methods to singlephase three-level inverters. Several space-vector modulation (SVM) methods are presented [17]-[21] by expanding the concept of the SVM of two-level inverters with more complexity and a more sophisticated calculation. On the other hand, the carrier-based modulation methods [22]-[24] for less calculation have been proposed. The discontinuous PWM (DPWM) [22], [23] to reduce the number of switching is presented by controlling one leg is not switched as a hybrid modulation of a two-level inverter [7]. The switching losses can be reduced but the current THD is increased. To control the current THD and efficiency, a novel DPWM method [24] is proposed by combining the unipolar PWM and DPWM. However, this research is clearly shown that the current ripple and current THD during DPWM are more than unipolar PWM.

In the above sense, this paper proposes a novel method to reduce voltage and current ripple using three-level full-bridge inverters with unipolar PWM. The main contributions of this paper are as follows. First, the simple carrier-based dipolar modulation [25] with few calculations and procedures is extended to the proposed method and all possible switching patterns of three-level inverters are also shown. Then, a concept of reference voltage generation from command output voltage and added zero voltage is also applied to unipolar modulation. Finally, the performance of two-level inverters and three-level inverters are compared.

\section{THE PROPOSED METHOD}

\subsection{Structure and basic equations of carrier-based dipolar modulation}

Three-level inverters are similar to two-level inverters in that they require a direct current supply. However, three-level inverters use three-levels of direct voltage from two capacitors that are connected in a series to divide half of the bus voltage. The equivalent circuits of three-level inverters are shown in Figure 1, where the three-level input bus voltage is obtained from the positive bus voltage $v_{P}$, the center bus voltage $v_{0}$, and the negative bus voltage $v_{N}$. The relationships between the voltages of the input and output sides for halfbridge inverters can be described by (1) and (2).

$$
\begin{aligned}
& v_{o}=v_{o}^{*}+v_{Z}=\left[\begin{array}{lll}
m_{11} & m_{12} & m_{13}
\end{array}\right]\left[\begin{array}{l}
v_{P} \\
v_{0} \\
v_{N}
\end{array}\right] \\
& m_{11}+m_{12}+m_{13}=1
\end{aligned}
$$

Where, $v_{o}^{*}$ and $v_{o}$ are command and output voltage respectively. $v_{Z}$ is zero-sequence voltage. $m_{11}$ and $m_{12}$ are duty cycles of three-level half-bridge inverters.

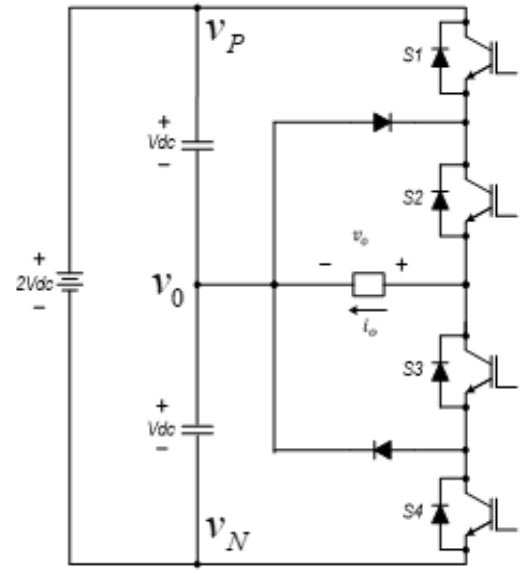

(a)

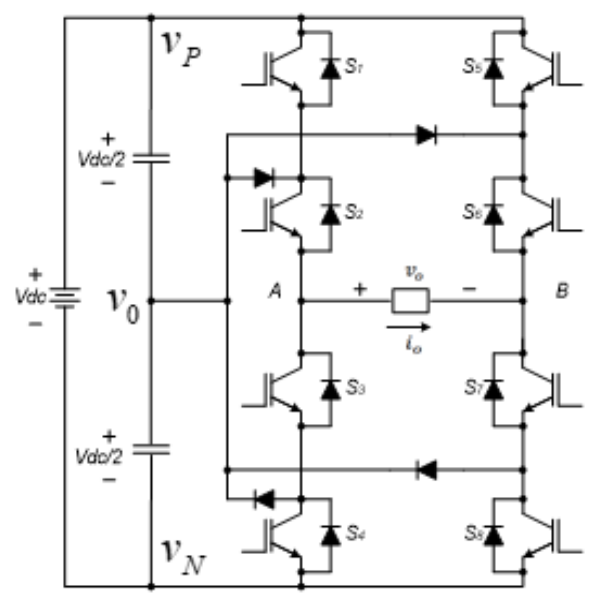

(b)

Figure 1. Structure of single-phase three-level inverter; (a) half-bridge and (b) full-bridge 
Figure 1 (a) shows a single-phase three-level half-bridge inverter scheme of which the output voltage is directly related to the current flow of the four switches. If switches $S_{1}$ and $S_{2}$ conduct the current, the output voltage will connect to the input positive bus voltage $v_{P}$. Then, if switches $S_{2}$ or $S_{3}$ conduct the current, the output voltage will connect to the center bus voltage $v_{0}$. Finally, if switches $S_{3}$ and $S_{4}$ conduct the current, the output voltage will connect to the input negative bus voltage $v_{N}$. A relationship between the output voltage and switching states is shown in Table 1.

Table 1. A relationship between output voltages and switching states for half-bridge inverters

\begin{tabular}{ccccccc}
\hline DC bus voltage & Output voltage $v_{o}$ & $S_{1}$ & $S_{2}$ & $S_{3}$ & $S_{4}$ & $i_{o}$ \\
\hline$v_{P}$ & $+\mathrm{Vdc}$ & On & On & Off & Off & $>0$ \\
$v_{0}$ & 0 & Off & On & Off & Off & $>0$ \\
$v_{0}$ & 0 & Off & Off & On & Off & $<0$ \\
$v_{N}$ & $-\mathrm{Vdc}$ & Off & Off & On & On & $<0$ \\
\hline
\end{tabular}

\subsection{Concept of carrier-based dipolar modulation}

According to Figure 1, the scheme of the single-phase three-level inverters can be easily rewritten, as shown in Figure 2, which now has three-level t-type neutral point clamped (3L-TNPC) switches that support the configuration in [26]. The carrier-based modulation technique of three-level inverters is different from that of two-level inverters at which two sets of the carrier wave and reference voltage are compared [27] and is called carrier-based dipolar modulation. The concept of this modulation is extended to generate the switching signals for three-phase three-level inverters [28]-[30].

Although the modulation method to generate a signal that drives the switches for three-level inverters is more complex than that of two-level inverters, using a carrier-based dipolar modulation can reduce the complexity. This modulation technique that generates the signal to drive the switches infers the relationship in generating the reference voltages $u_{P}^{*}, u_{N}^{*}$ from command voltage $v_{o}^{*}$, which can be shown in (3).

$$
\begin{aligned}
& v_{o}^{*}=u_{P}^{*}+u_{N}^{*} \\
& v_{Z}=v_{Z P}+v_{Z N}=0 \\
& v_{o}=v_{o}^{*}+v_{Z}=\underbrace{\left(u_{P}^{*}+v_{Z P}\right)}_{u_{P}}+\underbrace{\left(u_{N}^{*}+v_{Z N}\right)}_{u_{N}}
\end{aligned}
$$

Where, $u_{P}^{*}, u_{N}^{*}$ are positive and negative command voltages, $u_{P}, u_{N}$ are positive and negative references and $v_{Z P}, v_{Z N}$ are positive and negative zero-sequence voltages. Generally, the carrier wave and the reference signal are equal to one unit. In this paper, on the other hand, the maximum and minimum values of carrier wave used to describe the modulation concept depend on the input voltage or DC bus voltage and the value of reference signal is upon the desired output voltage, as demonstrated in Figure 3.

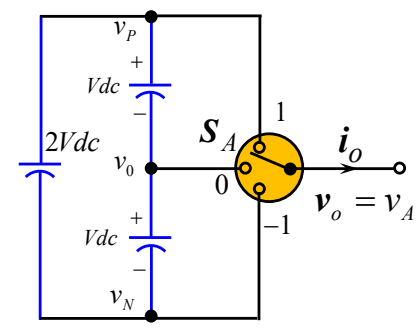

(a)

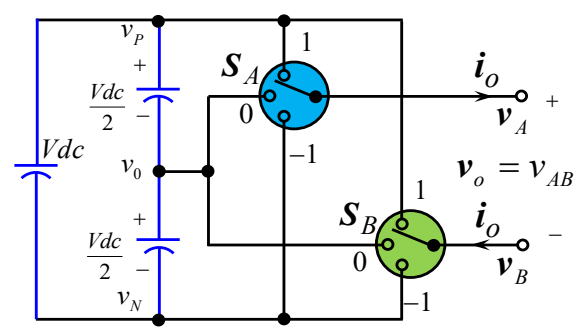

(b)

Figure 2. Simplified structure of single-phase three-level inverter; (a) half-bridge and (b) full-bridge

Research [25] proposed the concept of carrier-based dipolar modulation from the commanded voltage for three-phase three-level inverters. This can be applied to single-phase inverters. The steps are as follows. First, the commanded output voltage, as shown in Figure 3 (a), is divided into two parts: positive voltage command $u_{P}^{*}$, which is built from the positive bus, and the negative voltage command $u_{N}^{*}$, which is built from the negative bus, as shown in Figure 3 (b). Then, the positive zero-sequence voltage $v_{Z P}$ and positive voltage command $u_{P}^{*}$ are added and the positive reference voltage $u_{P}$ is moved up or down to the desired position. 
Besides, the negative voltage command $u_{N}^{*}$ and the appropriate positive zero-sequence voltage $v_{Z N}$, are added at which the values are independent and the reference voltage $u_{N}$ is moved to the desired position. However, in the case of a half-bridge scheme, $v_{Z P}$ and $v_{Z N}$ are directly related. If $v_{Z P}$ is decreased, the $v_{Z N}$ is also decreased and $v_{Z}$ must be equal to zero, as shown in Figure 3 (c) or Figure 3 (d). After that, the reference voltages $u_{P}$ and $u_{N}$ in Figure 3 (d) are normalized. Then $U_{P}, U_{N}$ which are used to compare to the carrier-based dipolar, can be obtained as shown in Figure 3 (e). Finally, the different modulation schemes on $U_{P}, U_{N}$ as shown in Figure 4.

Figure 4 describes the carrier-based dipolar modulation for three-level inverters. As seen in the above figure, the different addition of zero voltage $v_{Z P}, v_{Z N}$ gives PWM mode for each leg as follows: dipolar switching (d), unipolar switching (u), bipolar switching (b), and non-switching (n) that cover all possible switching patterns of three-level inverters. Here, an integer and letters " $d$ " " $u$ " "b" or " $n$ " are used to represent a PWM mode. For example, $<1 \mathrm{u} 1 \mathrm{~d}>$ PWM means that one leg is in unipolar mode and one leg is in dipolar mode.

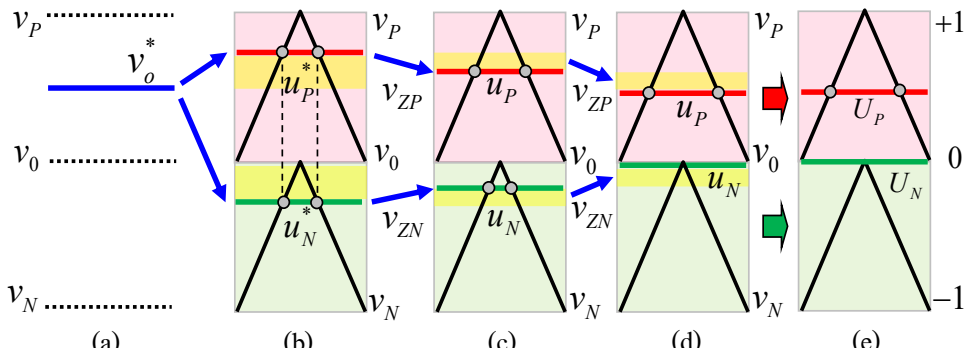

(a) (b)

(c)

(d)

(e)

Figure 3. Concept of carrier-based dipolar modulation; (a) commanded voltage, (b) positive and negative voltage commands, (c) reference voltages, (d) reference voltages for unipolar mode, and (e) reference signals

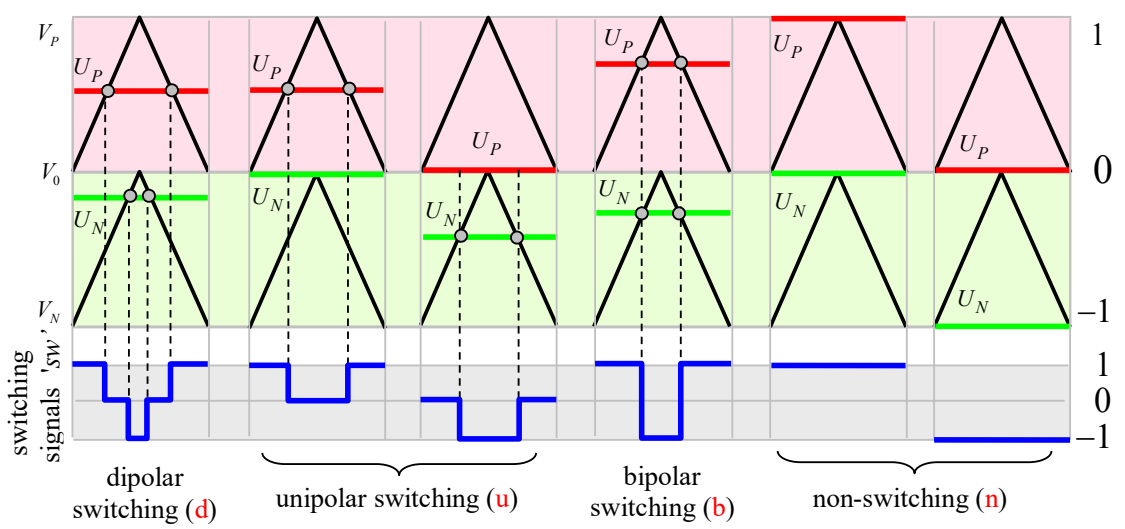

Figure 4. PWM mode for three-level inverters [25]

\section{THE RESEARCH METHOD}

From Figure 2 (b), the relationship between the output voltage and switching states is shown in Table 2. And the relationship between the output voltage and input voltage can be described by (6) and (7).

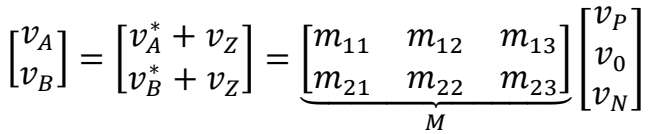

$$
\begin{aligned}
& 0 \leq m_{i j} \leq 1, \quad i=\{1,2\}, j=\{1,2,3\} \sum_{j=1}^{3} m_{i j}=1 \text {, }
\end{aligned}
$$

The carrier-based modulation method for full-bridge inverters differs from half-bridge inverters, as shown in Figures 2 (a) and (b) respectively, by adding zero voltage $v_{Z}$ the same as the three-phase inverters because the output voltage of full-bridge inverters is different for A-leg and B-leg voltages, as shown in (8).

Novel ripple reduction method using three-level inverters with unipolar PWM (Paiboon Kiatsookkanatorn) 


$$
v_{o}^{*}=v_{A B}^{*}=v_{A}^{*}-v_{B}^{*}
$$

Where,

$$
v_{A}^{*}=-v_{B}^{*}
$$

and

$$
v_{o}=v_{A B}=\left(v_{A}^{*}+v_{z}\right)-\left(v_{B}^{*}+v_{z}\right)
$$

resulting in

$$
\left.\begin{array}{l}
v_{A}^{*}+v_{z}=\left(u_{A P}^{*}+v_{Z P}\right)+\left(u_{A N}^{*}+v_{Z N}\right) \\
v_{B}^{*}+v_{z}=\left(u_{B P}^{*}+v_{Z P}\right)+\left(u_{B N}^{*}+v_{Z N}\right)
\end{array}\right\}
$$

Here, $v_{A B}^{*}, v_{A B}$ are command and output voltage between A-leg and B-leg. $v_{A}^{*}, v_{A}$ are command and output Aleg voltage and $v_{B}^{*}, v_{B}$ are command and output B-leg voltage. $u_{A P}^{*}, u_{B P}^{*}$ are positive output voltage commands A-leg and B-leg. $u_{A N}^{*}, u_{B N}^{*}$ are negative output voltage commands A-leg and B-leg. $u_{A P}, u_{B P}$ and $u_{A N}, u_{B N}$ are positive and negative output voltages A-leg and B-leg, respectively.

Table 2. A relationship between output voltages and switching states for full-bridge inverters

\begin{tabular}{cccccccccc}
\hline Modes & 1 & 2 & 3 & 4 & 5 & 6 & 7 & 8 & 9 \\
\hline$S_{A}$ & 1 & 1 & 1 & 0 & 0 & 0 & -1 & -1 & -1 \\
$S_{B}$ & 1 & 0 & -1 & 1 & 0 & -1 & 1 & 0 & -1 \\
$v_{A 0}$ & $v_{P}$ & $v_{P}$ & $v_{P}$ & $v_{0}$ & $v_{0}$ & $v_{0}$ & $v_{N}$ & $v_{N}$ & $v_{N}$ \\
$v_{B 0}$ & $v_{P}$ & $v_{0}$ & $v_{N}$ & $v_{P}$ & $v_{0}$ & $v_{N}$ & $v_{P}$ & $v_{0}$ & $v_{N}$ \\
$v_{A B}$ & 0 & $V_{d c} / 2$ & $V_{d c}$ & $-V_{d c} / 2$ & 0 & $V_{d c} / 2$ & $-V_{d c}$ & $-V_{d c} / 2$ & 0 \\
\hline
\end{tabular}

Figure 5 shows carrier-based dipolar modulation for full-bridge three-level inverters. In this case, commanded voltages consist of A-leg voltage $v_{A}^{*}$ and B-leg voltage $v_{B}^{*}$ that are out of phase 180 degrees, as shown in Figure 5 (a). In the double carrier-based dipolar modulation, commanded voltages in each leg are divided into two parts: positive A-leg voltage command $u_{A P}^{*}$ and negative A-leg voltage command $u_{A N}^{*}$. For the B-leg case they are the same as A-leg, as shown in Figure 5 (b). Then, these positive and negative voltage commands are added by the appropriate positive and negative zero voltages $v_{Z P}$ and $v_{Z N}$. As a result, reference voltages $u_{P}$ and $u_{N}$ are moved to the desired position, as shown in Figure 5 (c) or Figure 5 (d). Figure 5 (c) is $<\ln 1 \mathrm{~b}>$ PWM while Figure $5(\mathrm{~d})$ is $<2 \mathrm{u}>$ PWM. For full-bridge inverters, adding zero voltages $v_{Z P}$ and $v_{Z N}$ are independent and differ from half-bridge inverters. Finally, the reference signals $\left[U_{P}\right]$ and $\left[U_{N}\right]$ are obtained by normalizing $u_{P}$ and $u_{N}$ in Figure 5 (d) with DC bus voltage, as shown in Figure 5 (e). This concept is the novel carrier-based modulation method for single-phase three-level inverters.

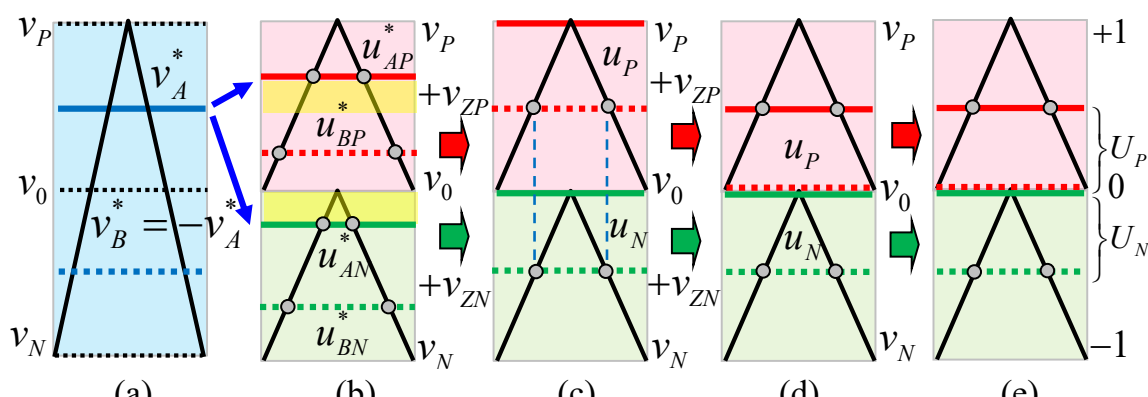

(a)

(b)

(c)

(d)

(e)

Figure 5. Carrier-based dipolar modulation for full-bridge three-level inverters; (a) commanded voltages,

(b) $<2$ d $>$ PWM, (c) $<1 \mathrm{n} 1 \mathrm{~b}>$ PWM, (d) $<2 \mathrm{u}>$ PWM, and (e) reference signals for $<2 \mathrm{u}>$ PWM

According to the general equation of modulation $M$ for full-bridge inverters in (6), the function of zero voltage modulation can be separated as (11). 


$$
M=M^{\prime}+M_{0}=\underbrace{\left[\begin{array}{lll}
m_{11}^{\prime} & m_{12}^{\prime} & m_{13}^{\prime} \\
m_{21}^{\prime} & m_{22}^{\prime} & m_{23}^{\prime}
\end{array}\right]}_{\left[M^{\prime}\right]}+\underbrace{\left[\begin{array}{ccc}
X & Y & Z \\
X & Y & Z
\end{array}\right]}_{\left[M_{0}\right]}
$$

Where,

$$
\left[M^{\prime}\right]=\frac{1}{v_{P}^{2}+v_{0}^{2}+v_{N}^{2}}\left[\begin{array}{c}
v_{A}^{*} \\
v_{B}^{*}
\end{array}\right]\left[\begin{array}{lll}
v_{P} & v_{0} & v_{N}
\end{array}\right]
$$

when the general equation of modulation function $M$ from (6) is replaced by another (11). In this case, (6) then becomes (12).

$$
\left[\begin{array}{l}
v_{A} \\
v_{B}
\end{array}\right]=\left[\begin{array}{l}
v_{A}^{*}+v_{Z} \\
v_{B}^{*}+v_{Z}
\end{array}\right]=\left[\begin{array}{l}
m_{11}^{\prime}+X \\
m_{21}^{\prime}+X
\end{array}\right] v_{P}+\left[\begin{array}{l}
m_{12}^{\prime}+Y \\
m_{22}^{\prime}+Y
\end{array}\right] v_{0}+\left[\begin{array}{l}
m_{13}^{\prime}+Z \\
m_{23}^{\prime}+Z
\end{array}\right] v_{N}
$$

The output voltage and input voltage are compared to the middle point of DC bus voltage and the results are shown as (13).

$$
\left[\begin{array}{l}
v_{A}-v_{0} \\
v_{B}-v_{0}
\end{array}\right] \triangleq \underbrace{\left[\begin{array}{l}
m_{11}^{\prime}+X \\
m_{21}^{\prime}+X
\end{array}\right]\left(v_{P}-v_{0}\right)}_{u_{P}}+\underbrace{\left[\begin{array}{l}
m_{13}^{\prime}+Z \\
m_{23}^{\prime}+Z
\end{array}\right]\left(v_{N}-v_{0}\right)}_{u_{N}}
$$

and the zero voltage $v_{Z P}, v_{Z N}$ in (10) is derived from

$$
v_{Z P}=X\left[v_{P}-v_{0}\right], v_{Z N}=-Z\left[v_{0}-v_{N}\right]
$$

From (11) the allowable range of zero voltages $M_{0}$ are given by (15).

$$
\left.\begin{array}{l}
-\min \left(m_{11}^{\prime}, m_{21}^{\prime}\right) \leq X \leq 1-\max \left(m_{11}^{\prime}, m_{21}^{\prime}\right) \\
-\min \left(m_{12}^{\prime}, m_{22}^{\prime}\right) \leq Y \leq 1-\max \left(m_{12}^{\prime}, m_{22}^{\prime}\right) \\
-\min \left(m_{13}^{\prime}, m_{23}^{\prime}\right) \leq Z \leq 1-\max \left(m_{13}^{\prime}, m_{23}^{\prime}\right) \\
X+Y+Z=1
\end{array}\right\}
$$

According to Figure 4, it can be seen that unipolar switching gives low voltage level transition. In this paper, the minimum values of $X, Z$ are chosen to make a $<2 \mathrm{u}>\mathrm{PWM}$ true as represented in (16).

$$
\left.\begin{array}{l}
X=-\min \left(m_{11}^{\prime}, m_{21}^{\prime}\right) \\
Z=-\min \left(m_{12}^{\prime}, m_{22}^{\prime}\right)
\end{array}\right\}
$$

\section{RESULTS AND DISCUSSION}

Simulation is carried out to compare and analyze the output current and voltage ripple for single-phase inverters. Simulation conditions are shown in Table 3. Figures 6 and 7 show the results of two-level inverters and Figures 8 and 9 show the results of three-level inverters by using the proposed carrier-based modulation. From the above three modulations, Figures 6 (a) and 6 (b) are bipolar and unipolar modulations, respectively that give THD of voltage according to [5] and Figure 6 (c) is hybrid modulation accoding to report of [7]. A comparison of the output current ripple of each modulation is shown in Figure 7. From Figure 7, it is indicated that the the two-level inverters have high values in both the ripple voltage and ripple current. Though the method of modulation is chosen appropriately, the two-level inverter scheme can only produce the lowest voltage to Vdc. Thus, to achieve a lower voltage than Vdc, the three-level inverter scheme needs to be implemented.

Table 3. Simulation conditions

\begin{tabular}{cccc}
\hline Parameters & Value & Parameters & Value \\
\hline DC Bus Voltage & $\sqrt{2} * 220 \mathrm{~V}$ & Load & $R=100 \Omega, L=20 \mathrm{mH}$ \\
Output Voltage & $220 \mathrm{~V}, 50 \mathrm{~Hz}$ & Switching Frequency & $5 \mathrm{kHz}$ \\
\hline
\end{tabular}



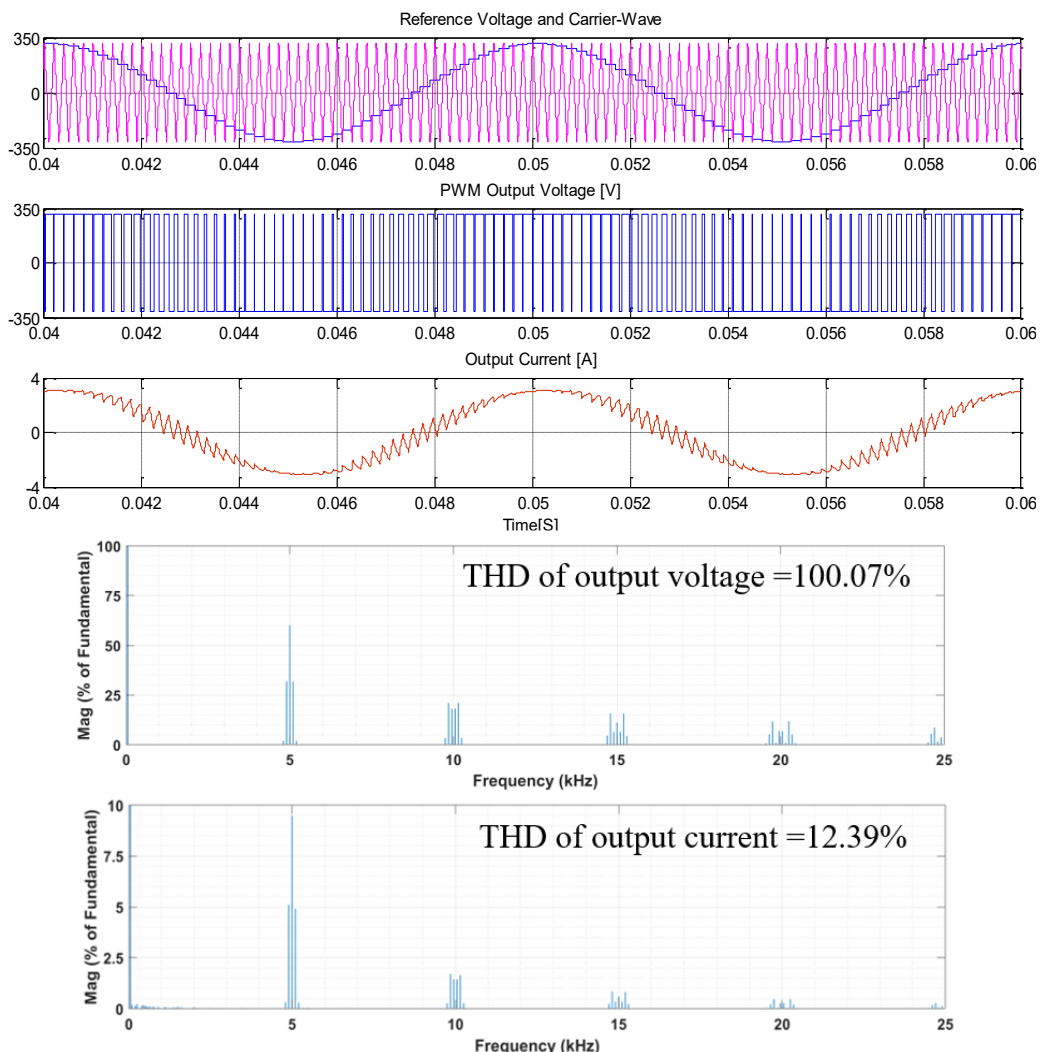

(a)
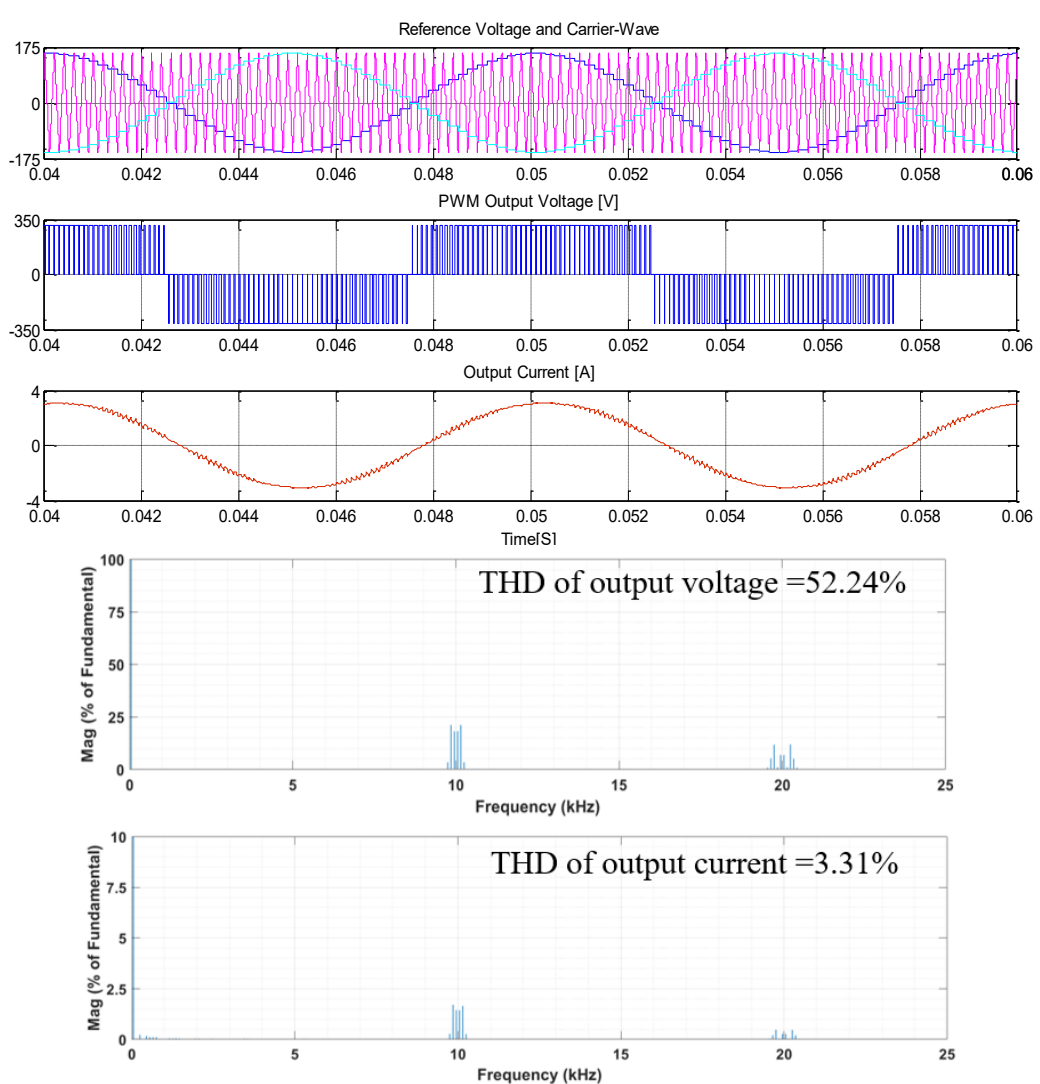

(b)

Figure 6. Voltage and current waveforms and spectrums for two-level full-bridge inverters; (a) bipolar modulation (2LFB-B) and (b) unipolar modulation (2LFB-U) 

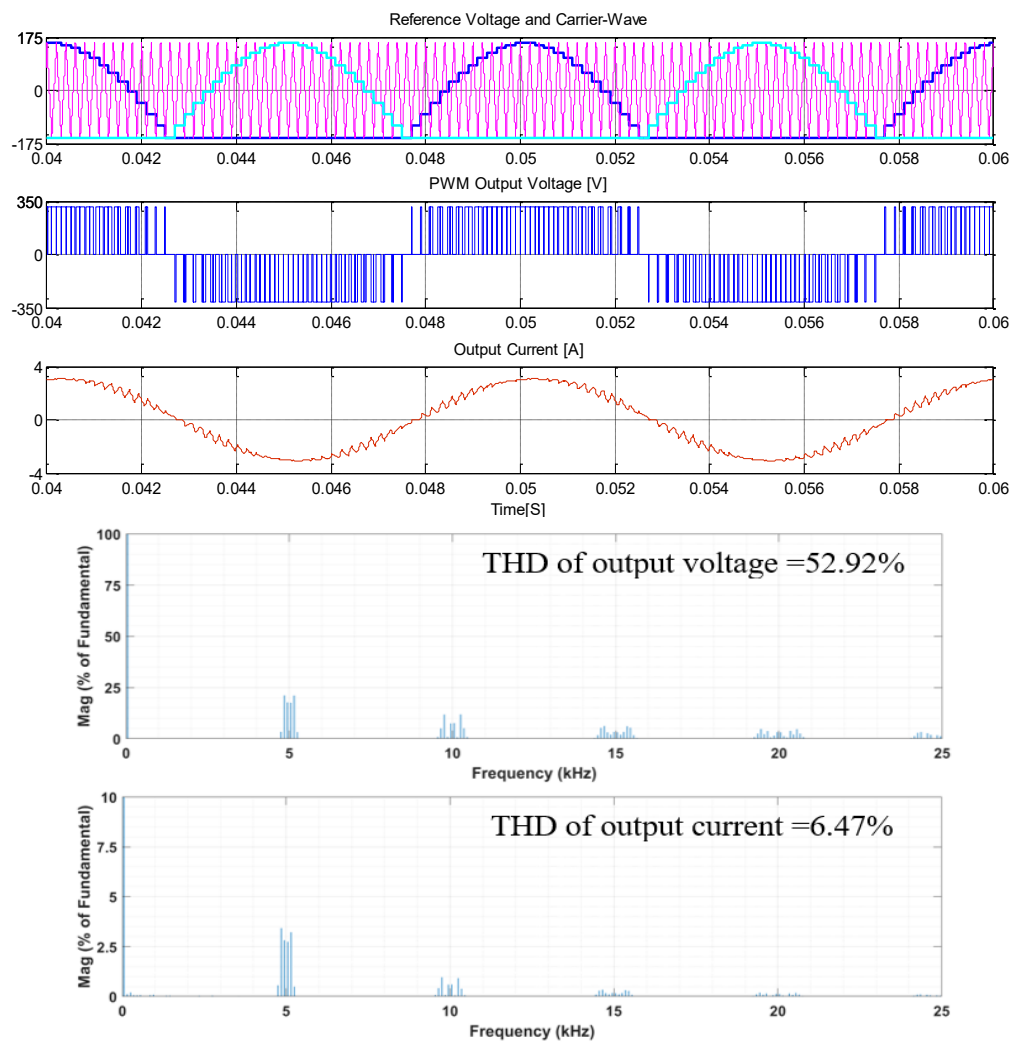

(c)

Figure 6. Voltage and current waveforms and spectrums for two-level full-bridge inverters; (c) hybrid modulation (2LFB-H) (continue)

Figure 8 (a) illustrates the unipolar modulation for a three-level half-bridge inverter. In this modulation, the positive voltage generates the positive bus while the negative voltage generates the negative bus, which has no direct transition from positive bus to negative bus. In addition, this modulation requires only two switching times $<1 \mathrm{u}>$ PWM. Compared to Figure 7 (c), the output voltage and the current waveform, including the voltage spectrum, have similar characteristics. Therefore, this modulation can be used to replace a two-level inverter with a hybrid modulation. Figure 8 (b) describes the unipolar modulation of two legs $(<2 u>$ PWM) for a three-level full-bridge inverter and indicates the change of the output voltage level is minimized to Vdc/2 only. As a result, the changes of $d v / d t$ are also minimized to half in the case of half-bridge configuration. Hence, the output ripple voltage that can be observed through the sine wave output is significantly reduced. The output current ripple can be compared with the case of a half-bridge, as shown in Figure 9.

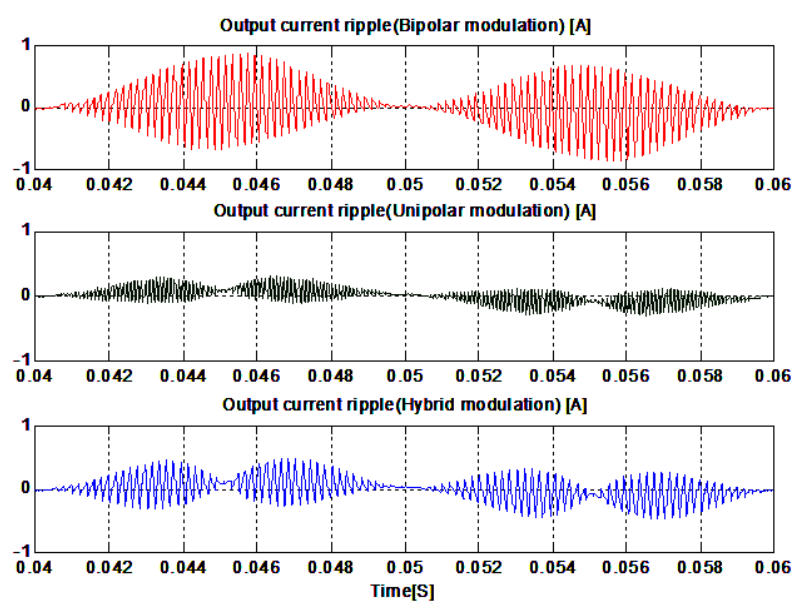

Figure 7. The output current ripple of two-level inverters

Novel ripple reduction method using three-level inverters with unipolar PWM (Paiboon Kiatsookkanatorn) 

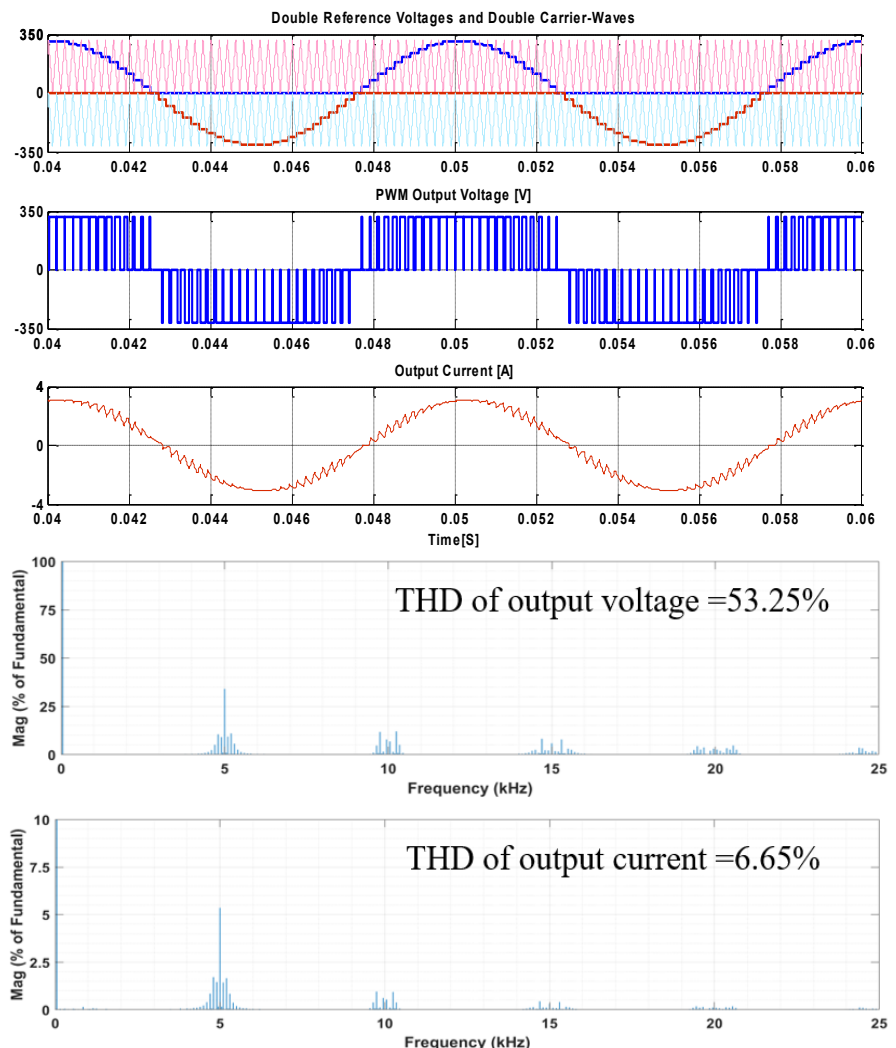

(a)
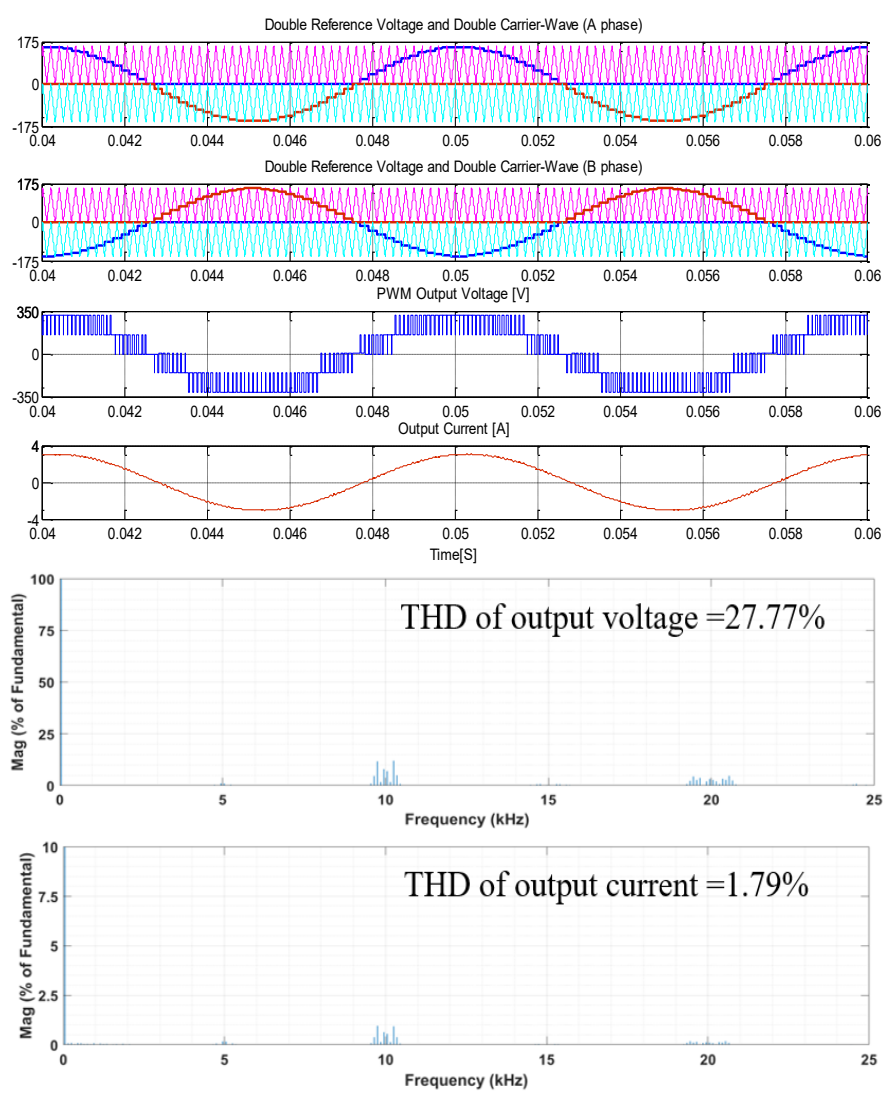

(b)

Figure 8. Voltage and current waveforms and spectrums for three-level inverter with a carrier-based dipolar modulation to unipolar switching; (a) half-bridge (3LHB-U) and (b) full-bridge (3LFB-2U) 

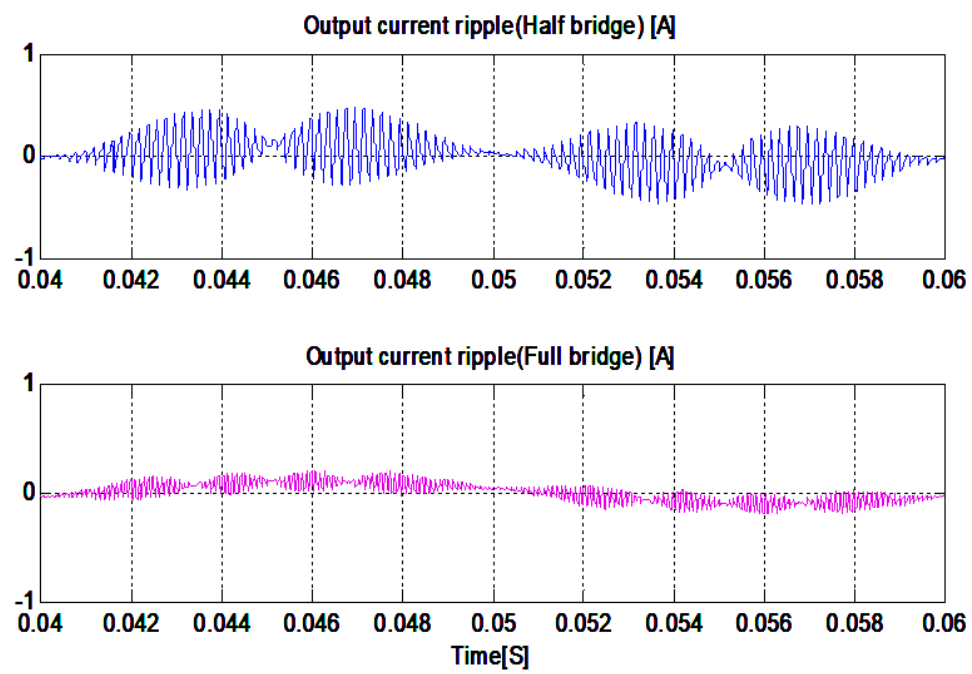

Figure 9. The output current ripple of three-level inverters

It is shown in Figure 9 that the output current ripple of three-level full-bridge inverters is very low. It is confirmed that the viewpoint of the proposed three-level inverter to reduce ripple is realized and using carrier-based dipolar modulation to generate the switching signals for the three-level inverter is simple. This is similar to the modulation process of the two-level inverters. Furthermore, this dipolar modulation technique can also generate bipolar and dipolar switchings. Hence, the switching patterns have freedom except for the unipolar switching. For this reason, future studies will use this modulation to reduce the current ripple in DC link capacitors too.

From the presented guidelines, the characteristics of single-phase inverters can be compared, as shown in Table 4. It is shown that the voltage level transition of a two-level inverter with bipolar modulation (2LFB-B) is high to $2 \mathrm{Vdc}$ and it can be reduced to $\mathrm{Vdc}$ when modulation is replaced by unipolar modulation (2LFB-U). The output voltage frequency of this modulation is increased twice the switching frequency. As the result, the current ripple is reduced but the switching losses are high. The switching losses can be decreased by using hybrid modulation (2LFB-H) because this modulation will give the output voltage frequency reducing to the switching frequency. However, the change of output voltage frequency makes the current ripple to be high. On the other hand, three-level inverter utilization to reduce the current ripple controlling the low voltage level transition by choosing the unipolar modulation but the characteristics in Table 3 indicated that three-level halfbridge inverters (3LHB-U) are like 2LFB-H. The voltage level transition of both is Vdc so if we want to have the only $\mathrm{Vdc} / 2$, the three-level inverter changes from half-bridge to full-bridge and still unipolar modulation (3LFB-2U). This modulation gives the output voltage frequency twice the switching frequency as 2LFB-U but the current ripple of $3 \mathrm{LFB}-2 \mathrm{U}$ is lower. Because of the low voltage level transition, the voltage stress of switches is low too. Although the number of switchings in a period is four, switching losses are still low. Furthermore, 3LFB-2U also gives low total harmonics distortion of voltage and current by $27.77 \%$ and $1.79 \%$, respectively. Therefore, it can be confirmed that voltage level transition significantly affects the performance of inverters. The factors on low voltage level transition come from the inverter structure and proper PWM mode. Thus, it can be concluded that the proposed inverters have been a high performance that can be able to apply the grid-connected inverters for the photovoltaic system.

Table 4. Characteristics of two-level and three-level inverters

\begin{tabular}{|c|c|c|c|c|c|}
\hline Features & 2LFB-B[5] & 2LFB-U[5] & 2LFB-H[7] & 3LHB-U & 3LFB-2U \\
\hline PWM mode & $<2 b>$ & $<2 \mathrm{~b}>$ & $<\ln 1 \mathrm{~b}>$ & $<1 \mathrm{u}>$ & $<2 \mathrm{u}>$ \\
\hline Voltage level transition & $2 \mathrm{Vdc}$ & Vdc & Vdc & Vdc & $\mathrm{Vdc} / 2$ \\
\hline Maximum of current ripple peak-to-peak value (A) & 1.52 & 0.45 & 0.72 & 0.73 & 0.23 \\
\hline PWM output voltage & fs & $2 \mathrm{fs}$ & fs & fs & $2 \mathrm{fs}$ \\
\hline Switching number / Ts & 4 & 4 & 2 & 2 & 4 \\
\hline Switch voltage stress & Vdc & Vdc & Vdc & Vdc & $\mathrm{Vdc} / 2$ \\
\hline Switching losses & Fair & Fair & Low & Low & Low \\
\hline$\% \mathrm{THDv}$ & 100.07 & 52.24 & 52.92 & 53.25 & 27.77 \\
\hline$\%$ THDi & 12.39 & 3.31 & 6.47 & 6.65 & 1.79 \\
\hline
\end{tabular}




\section{CONCLUSION}

This paper proposes a novel method to reduce output ripple for the single-phase inverters by using three-level inverters in combination with unipolar modulation. We applied a carrier-based dipolar modulation of three-phase inverters to single-phase inverters by expanding the concept of modulation command voltage as a reference voltage as the same as in two-level inverters. Thus, the generation of the switching signals can be simplified. The simulation results show that the three-level half-bridge inverters with unipolar modulation (3LHB-U) have the same performance at the same level as two-level full-bridge inverters with hybrid modulation (2LFB-H). Therefore, the concept of ripple reduction in single-phase inverters can be realized by using three-level full-bridge inverters (3LFB-2U), which provide very low levels of change in $d v / d t$. Hence, the change of voltage is not only minimized to $\mathrm{Vdc} / 2$, but the waveform is also closer to the sine wave. As a result, the harmonic voltages and the harmonic currents are at a lowered level and the stress voltage at the switch is minimized to $\mathrm{Vdc} / 2$. Moreover, the switching losses are also low because the voltage across power devices is half of the DC bus voltage. Comparing with unipolar modulation methods, this proposed modulation method can utilize the bipolar and dipolar switchings which are maybe necessary to reduce the current ripple in DC link capacitors.

\section{ACKNOWLEDGEMENTS}

This work is funded by Rajamangala University of Technology Suvarnabhumi.

\section{REFERENCES}

[1] S. B. Kjaer, J. K. Pedersen, and F. Blaabjerg, "A review of single-phase grid-connected inverters for photovoltaic modules," in IEEE Transactions on Industry Applications, vol. 41, no. 5, pp. 1292-1306, Sept.-Oct. 2005, doi: 10.1109/TIA.2005.853371.

[2] Q. Li and P. Wolfs, "A review of the single phase photovoltaic module integrated converter topologies with three different DC link configurations," in IEEE Transactions on Power Electronics, vol. 23, no. 3, pp. 1320-1333, May 2008, doi: 10.1109/TPEL.2008.920883.

[3] R. Teodorescu, M. Liserre and P. Rodriguez, Grid Converters for Photovoltaic and Wind Power Systems, Chap. 3, New York, USA: Wiley, 2011, pp. 37-38.

[4] N. Mohan, T. M. Undeland, and W. P. Robbins, Power Electronics: Converters, Applications and Design, 2nd ed. New York, USA: Wiley, 1995.

[5] A. Namboodiri and H. S. Wani, "Unipolar and bipolar PWM inverter," International Journal for Innovative Research in Science \& Technology, vol. 1, no. 7, pp. 237-243, 2014.

[6] X. Mao, R. Ayyanar, and H. K. Krishnamurthy, "Optimal variable switching frequency scheme for reducing switching loss in single-phase inverters based on time-domain ripple analysis," in IEEE Transactions on Power Electronics, vol. 24, no. 4, pp. 991-1001, April 2009, doi: 10.1109/TPEL.2008.2009635.

[7] Ray-Shyang Lai and K. D. T. Ngo, "A PWM method for reduction of switching loss in a full-bridge inverter," in IEEE Transactions on Power Electronics, vol. 10, no. 3, pp. 326-332, May 1995, doi: 10.1109/63.387998.

[8] G. Shen, D. Xu, L. Cao, and X. Zhu, "An improved control strategy for grid-connected voltage source inverters with an LCL filter," in IEEE Transactions on Power Electronics, vol. 23, no. 4, pp. 1899-1906, July 2008, doi: 10.1109/TPEL.2008.924602.

[9] H. Kim and S.K. Sul, "A novel filter design for output LC filters of PWM inverters," Journal of Power Electronics. vol. 11, no. 1, pp. 74-81, 2011, doi: 10.6113/JPE.2011.11.1.074.

[10] R. J. Pasterczyk, J. Guichon, J. Schanen and E. Atienza, "PWM inverter output filter cost-to-losses tradeoff and optimal design," in IEEE Transactions on Industry Applications, vol. 45, no. 2, pp. 887-897, 2009, doi: 10.1109/TIA.2009.2013605.

[11] K. Kim, T. Shimizu, K. Takano and H. Ishii, "Dynamic iron loss measurement method for an AC filter inductor on a PWM inverter," 2007 European Conference on Power Electronics and Applications, 2007, pp. 1-9, doi: 10.1109/EPE.2007.4417517.

[12] Q. Li, D. Jiang and Y. Zhang, "Analysis and calculation of current ripple considering inductance saturation and its application to variable switching frequency PWM," in IEEE Transactions on Power Electronics, vol. 34, no. 12, pp. 12262-12273, Dec. 2019, doi: 10.1109/TPEL.2019.2903884.

[13] A. Nabae, I. Takahashi and H. Akagi, "A new neutral-point-clamped PWM inverter," in IEEE Transactions on Industry Applications, vol. IA-17, no. 5, pp. 518-523, Sept. 1981, doi: 10.1109/TIA.1981.4503992.

[14] L. Zhang, K. Sun, L. Feng, H. Wu and Y. Xing, "A family of neutral point clamped full-bridge topologies for transformerless photovoltaic grid-tied inverters," in IEEE Transactions on Power Electronics, vol. 28, no. 2, pp. 730-739, Feb. 2013, doi: 10.1109/TPEL.2012.2205406.

[15] D. Selvabharathi, et al., "Simulation of zeta converter based 3-level NPC inverter with PV system," Indonesian Journal of Electrical Engineering and Computer Science, vol. 12, no. 1, pp. 1-6, 2018, doi: 10.11591/ijeecs.v12.i1.pp1-6. 
[16] G. Fu, and X. Li, "Research on neutral-point potential control of a three-level inverter," Indonesian Journal of Electrical Engineering and Computer Science, vol. 14, no. 1, pp. 20-28, 2019. Doi: 10.11591/ijeecs.v14.i1.pp20-28.

[17] T. E. Shults, O. O. Husev and F. Blaabjerg, "Space vector pulse width modulation strategy for single-phase threelevel CIC T-source inverter," 2016 17th International Conference of Young Specialists on Micro/Nanotechnologies and Electron Devices (EDM), 2016, pp. 600-606, doi: 10.1109/EDM.2016.7538806.

[18] J. Guzman-Guemez, D. S. Laila and S. M. Sharkh, "State-space approach for modelling and control of a single-phase three-level NPC inverter with SVPWM," 2016 IEEE Power and Energy Society General Meeting (PESGM), 2016, pp. 1-5, doi: 10.1109/PESGM.2016.7741355.

[19] Z. H. Ali, J. Zhao, E. Manla, J. Ma and W. Song, "Novel direct power control of single-phase three-level SVPWM inverter for photovoltaic generation," 2017 IEEE Power \& Energy Society Innovative Smart Grid Technologies Conference (ISGT), 2017, pp. 1-5, doi: 10.1109/ISGT.2017.8085959.

[20] T. E. Shults, A. S. Filatova, M. A. Dybko and O. O. Husev, "SVPWM capacitor balancing method for single-phase three-level NPC impedance-source inverters," 2018 19th International Conference of Young Specialists on Micro/Nanotechnologies and Electron Devices (EDM), 2018, pp. 6403-6407, doi: 10.1109/EDM.2018.8434962.

[21] T. E. Shults, O. Husev, F. Blaabjerg, C. Roncero-Clemente, E. Romero-Cadaval and D. Vinnikov, "Novel space vector pulsewidth modulation strategies for single-phase three-level NPC impedance-source inverters," in IEEE Transactions on Power Electronics, vol. 34, no. 5, pp. 4820-4830, May 2019, doi: 10.1109/TPEL.2018.2859194.

[22] S. Lee, J. Lee and K. Lee, "Novel switching strategy for high-efficiency of single-phase three-level inverters," 2014 IEEE Conference on Energy Conversion (CENCON), 2014, pp. 342-347, doi: 10.1109/CENCON.2014.6967527.

[23] Z. Wang, X. Li, X. Xing and C. Zhang, "Improved modulation strategy with reduced switching loss for single-phase three-level t-type inverter," 2020 IEEE Applied Power Electronics Conference and Exposition (APEC), 2020, pp. 2506-2513, doi: 10.1109/APEC39645.2020.9123996.

[24] J. Lee, R. Kwak and K. Lee, "Novel discontinuous PWM method for a single-phase three-level neutral point clamped inverter with efficiency improvement and harmonic reduction," in IEEE Transactions on Power Electronics, vol. 33, no. 11, pp. 9253-9266, Nov. 2018, doi: 10.1109/TPEL.2018.2794547.

[25] P. K. Sookkanatorn and S. Sangwongwanich, "Development of a carrier-based PWM for 3-level inverters," Ladkrabang Engineering Journal, vol 32, no 2, pp. 13-18, 2020.

[26] Silicon Carbide Power Modules, Semikron, [Online]. Available: https://www.semikron.com/innovationtechnology/silicon-carbide-power-modules.html. (Accessed 25 Jan. 2021).

[27] B. Velaerts, P. Mathys, E. Tatakis and G. Bingen, "A novel approach to the generation and optimization of threelevel PWM wave forms for induction motor inverters," PESC '88 Record., 19th Annual IEEE Power Electronics Specialists Conference, 1988, pp. 1255-1262 vol.2, doi: 10.1109/PESC.1988.18269.

[28] A. Saengseethong and S. Sangwongwanich, "A new modulation strategy for capacitor voltage balancing in threelevel NPC inverters based on matrix converter theory," The 2010 International Power Electronics Conference ECCE ASIA -, 2010, pp. 2358-2365, doi: 10.1109/IPEC.2010.5543689.

[29] S. Sangwongwanich, "Double-carrier-based modulation theory of three-level inverters and a new discontinuous PWM for neutral-point voltage balancing," IECON 2012 - 38th Annual Conference on IEEE Industrial Electronics Society, 2012, pp. 4961-4966, doi: 10.1109/IECON.2012.6389571.

[30] S. Sangwongwanich and S. Paiboon, "Carrier-based realization of arbitrary space-vector PWM methods for threelevel inverters," 2018 International Power Electronics Conference (IPEC-Niigata 2018 -ECCE Asia), 2018, pp. 1642-1648, doi: 10.23919/IPEC.2018.8507929. 